überschritten haben, je eine so geartete Hypertrophie der Prostata, dass Störungen in der Harnausscheidung die Folge sind, - so kann, so paradox es klingen mag, eine Harnröhrenverengerung, falls sie die angegebene Berücksichtigung findet, immerhin als ein relativ glückliches Acquisit angeselıen werden.

Zugleich fällt dadurch aber auch der gegenüber der Urethrotomia interna und forcirten Dilatation so werthvollen quäst. Curmethode noch ein Vortheil mehr zu, gross genug, um in vollen Maasse berücksichtigt zu werden.

\section{Warum haben Harnröhrenstricturen so selten senile Prostata-Hypertrophie im Gefolge? \\ Von}

Dr. Carl Panli in Cöln.

Pitha - Kranklıeiten der männlichen Geschlechtsorgane - sagt „Bei der grossen Symptomenähnlichkeit der Prostatatumoren und Stricturen erscheint die Frage von Wichtigkeit: ob und inwiefern sich dieselben unter einander combiniren können? - Diese Frage wird durch die Erfahrung dahin heantwortet: dass Hypertrophie der Prostata und Stricturen der Harnröhre sich - wenngleich nicht absolut - ausschliessen. Dieses exclusive Verlıăltniss ist aber nicht allein durch die Altersdifferenz bedingt - - da die Hypertrophie der Prostata Attribut des Greisenalters ist, wälırend die Stricturen dem jungen Mannesalter eigen sind -, sondern auch darin begründet, dass Stricturen der Urethra erfahrungsgemäss gerade zur Atrophie der Prostata disponiren (Mercier.)“

Zur Verhütung von Missverständen wird vorweg benerkt, dass, wie dies auch schon im Vorstehenden angedeutet ist, hier die senile, unheilbare Vergrösserung der Vorsteherdrüse, welche bekanntlich im musculösen Theile derselben iłıren Sitz aufschlägt und ohne entzündliche Zufälle heranschleicht, in Frage kommt, nicht aber die bei Stricturen sehr liäufig sympathisch auftretende und der Rückbilılung fähige Anschwellung der Prostata, welche sich lediglich auf den drüsigen Apparat derselben erstreckt.

Woher kommt es nun, dass eine solche Vergesellschaftung gewöhnlich nicht nur nicht stattfindet, sondern dass sogar die fragliche Canalisationsstörung zum Gegentheil, zur Atroplie der Vorsteherdrüse, führt?

Zweifellos verdankt dieser Vorgang dem Drucke (Druckatrophie), welchen das zum $Z$ wecke einer Erweiterung der quäst. Stenose in die Harnröhre geführte Instrument auf die Prostata ausübt, seine Entstehung; desgleichen darf elenso bestimmt angenommen werden, dass da, wo die in Rede stehende Combination Platz gegriffen lat, entweder keine oder eine andere als die angegebene Behandlung zur Anwendung gekommen ist.

Zieht man die ungemein grosse Verloreitung jenes so schlimmen, weil meist den Tod verursachenden, Drüsenleidens in Erwägung - nach H. Thompson kommt auf 20 Männer, welclie das $\mathbf{5 5}$. Lebensjahr 